\title{
Air Flow through a Weft Passage of Profile Reed in Air Jet Looms
}

\author{
SHINTANI Ryuji* and OKAJIMA Atsushi** \\ * Industrial Research Institute of Ishikawa, Ro-1 Tomizu-machi, Kanazawa, 920-0223 Japan \\ ** Faculty of Engineering, Kanazawa University, 2-40-20 Kodatsuno, Kanazawa, 920-8667 Japan \\ Based on the Journal of the Textile Machinery Society of Japan, Vol.54, No.1, T9-T16(2001-1)
}

\begin{abstract}
An air jet loom equipped with a profile reed and sub-nozzles is able to weave wider fabrics at higher speed than other types. A study on the characteristics of airflow and behavior of the weft yarn in the weft passage area of the profile reed during inserting the weft yarn is very important. The velocity distributions of airflow issued from a sub-nozzle in the weft passage were measured in detail by a hot-wire anemometer. The motion of a weft yarn in the weft passage was also observed by photography.

The experimental results indicate that the shape of the lower jaw part of the profile reed affects positions of the maximum velocity of the air jet in a cross-section until the air jet runs into the bottom of the reed. When the front side of the profile reed is closed, the value of the maximum velocity in the weft passage is smaller than that under the normal condition because of increasing of flow leakage behind the profile reed. The position of the maximum velocity in the weft passage is found to coincide with the position of the maximum leakage from the profile reed. It is confirmed by photograph that a yarn tip is led through the weft passage by the jet issued from a sub-nozzle.
\end{abstract}

Keywords: air jet loom, airflow, weft passage, profile reed, hot-wire measurement

\section{Introduction}

For the weft insertion mechanisms of air jet looms (AJL), the profile reeds with sub-nozzle systems are the most advantageous in terms of improving high speed weaving and wider cloth width. Not only the airflow from the main nozzle and sub-nozzles but also the airflow in the weft passage is closely related to the flying state of the yarn at the time of weft insertion in this system. In order to manufacture high quality textiles with $\mathrm{AJ}$, it is necessary to establish optimum weaving conditions. These conditions include the supply air pressure and air injection timing for the main nozzle and sub-nozzles according to the kind of weft yarn.

Energy saving is the most important of the technical subjects related to AJL today. Research about the improvement in performance of main nozzles and sub-nozzles, which plays an important role for weft insertion, has been performed [1-4]. In the weft passage of a profile reed, Yoshida et al. [5] measured the flow velocity distribution in the horizontal section of the center of weft-yarn flying path, and they suggested that it was necessary to decide injection timing such that the weft yarn flies inside of the region of steady airflow as much as possible.

The purpose of this investigation is to realize on increase of flexibility and electric power reduction in AJL by establishing the relation between the airflow in the weft passage and the weft flying state during the weft insertion, and by establishing optimum weaving conditions according to the kind of weft yarn.

In a previous paper [6], the portion of the airflow that leaks to the back of the profile reed was fundamentally investigated, and it was shown clearly that leakage is in two positions behind the profile reed. The central position of leakage changes with the reed density and the supply pressure to a sub-nozzle. It was shown clearly that the jet issued from a sub-nozzle leaks not only to the back of a profile reed, but also to the front for some reed densities.

In this paper, the air velocity in the tunnel section of the profile reed that determines the weft passage was measured in detail under different leakage conditions without a weft yarn in order to determine how the leakage to the back or front of the profile reed influences the airflow in the weft passage. Furthermore, the relation between the tip position of weft yarn, whose another tip is fixed, and the velocity distribution in the weft passage was investigated.

\section{Nomenclature}

The main symbols used in this paper are shown below.

$Q_{0}$ : supply airflow rate to a sub-nozzle

$Q_{b}$ : leakage flow rate behind the profile reed

$Q_{i}$ : airflow rate in the weft passage

* Corresponding author Fax:+81-76-267-8090, E-mail:sintan@irii.go.jp 


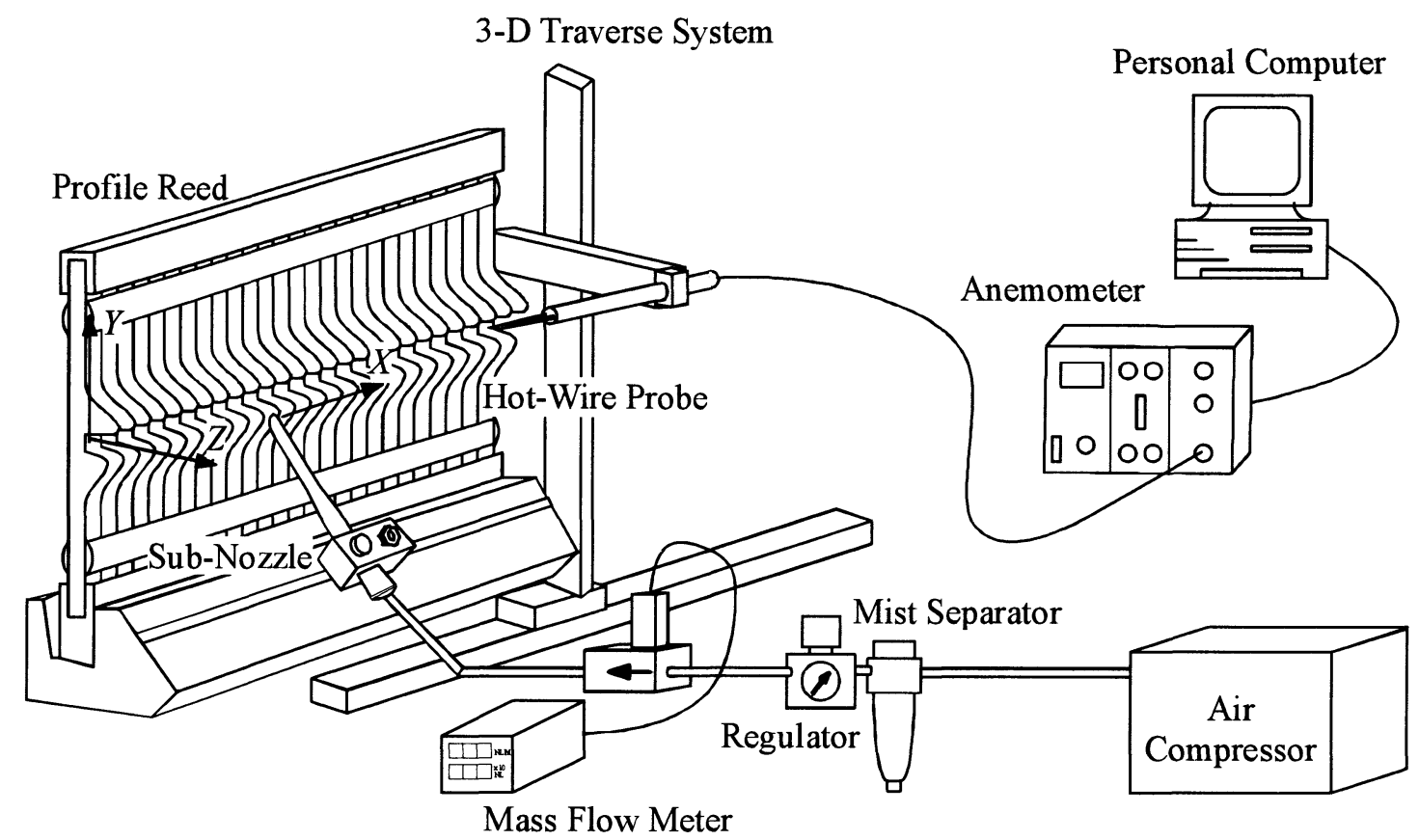

Fig. 1 Schematic diagram of a test apparatus

$U_{b}$ : time average air velocity behind the profile reed

$U_{i}$ : time average air velocity in the weft passage

$U_{m}$ : maximum air velocity in the weft passage

$s \quad:$ cavity ratio of the reed

$X \quad$ : axis in the direction of weft insertion (the origin being in a sub-nozzle outlet hole's center)

$Y \quad$ : axis in the vertical direction of a profile reed

$y_{m}$ : value of the $Y$-coordinate of the position in the weft passage where maximum velocity was observed

$Z \quad$ : axis in the horizontal direction of a profile reed

$z_{m}$ : value of the $Z$-coordinate of the position in the weft passage where maximum velocity was observed

$\theta_{a}:$ attachment angle of a sub-nozzle to the reed

$\theta_{y} \quad$ : lateral injection angle of a sub-nozzle [3]

$\theta_{z}$ : upward injection angle of a sub-nozzle [3]

\section{Experimental Equipment and Method}

\subsection{Experimental equipment}

The outline of experimental equipment is shown in Fig. 1. Experimental equipment included the bench test machine with a profile reed segment and a steel sub-nozzle. The profile reed segment had an overall length of $200 \mathrm{~mm}$, a density of $13.5 \mathrm{dents} / \mathrm{cm}$, profile dents with a thickness of $0.26 \mathrm{~mm}$ and a cavity ratio of $65 \%$. The sub-nozzle with an outlet diameter of $1.5 \mathrm{~mm}$ was mounted on the sley by means of a special attachment. The compressed air from the compressor was led to the sub-nozzle through a regulator and a mass flow meter. The coordinate system of the experiment is shown in Figs. 1 and 2. The direction of the weft insertion was the $X$-axis, and the center of the sub-nozzle outlet was the origin point of this axis. The vertical direction of the pro-

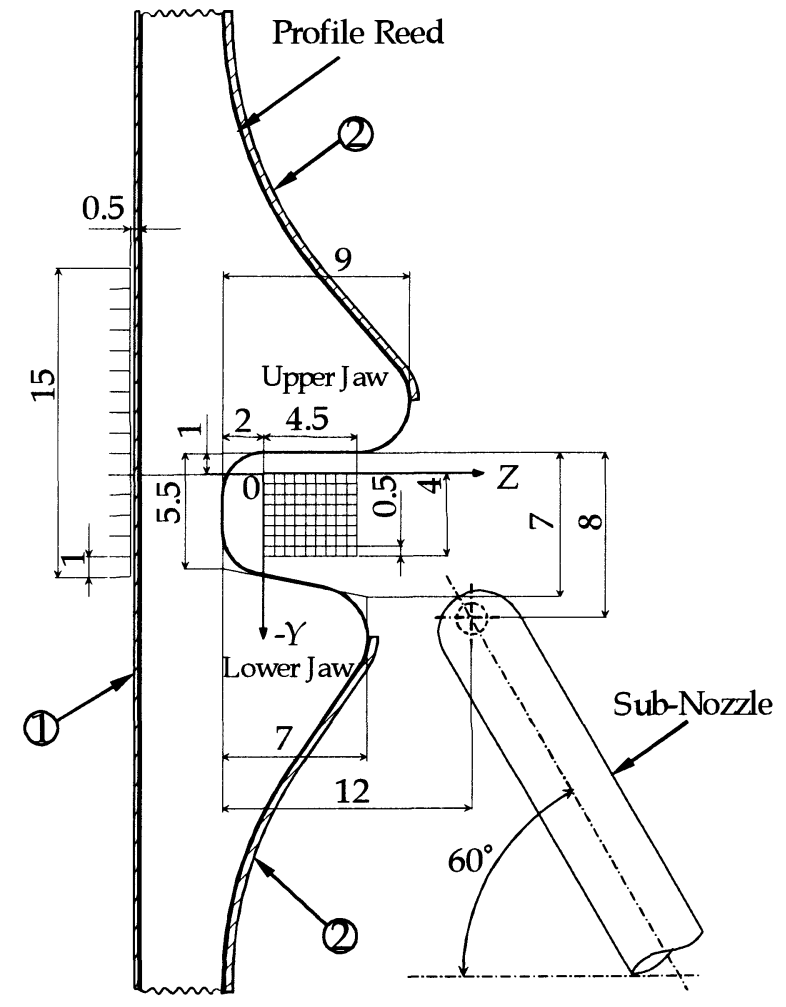

Fig. 2 Measurement points of air velocity on the profile reed

file reed segment was the $Y$-axis, and the horizontal direction of the profile reed segment was the $Z$-axis.

The sub-nozzle was attached to the sley at the fixed angle $\left(\theta_{a}=60 \mathrm{deg}\right)$ to the $Z$-axis, as shown in Fig. 2 . The air jet issued from the sub-nozzle was injected towards the slot bottom of the weft passage of a concave profile reed segment which had an upper jaw height of $9 \mathrm{~mm}$ and a lower 
jaw height of $7 \mathrm{~mm}$, and a slot bottom width of $5.5 \mathrm{~mm}$ as shown in the figure. The distance from the sub-nozzle's outlet center to the reed slot bottom was $12 \mathrm{~mm}$, and the distance from the sub-nozzle's outlet center to the upper jaw side is $8 \mathrm{~mm}$.

A hot-wire anemometer was used for measurement of the air velocity in the weft passage as well as behind the profile reed segment. The output analog voltage value from the hot-wire anemometer was proportional to velocity and was converted into digital value by a personal computer. The digital value was subsequently converted into velocity value by data processing. The sensor of the hot-wire anemometer was an I-type probe of tungsten wire with a diameter of 5 $\mu \mathrm{m}$ and a length of $1 \mathrm{~mm}$. In order to measure the velocity distribution, the hot-wire probe was driven by a 3-dimensional traverse system controlled by a personal computer, and it was moved to predetermined positions.

\subsection{Experimental method}

The experiment was conducted by injecting compressed air steadily from a sub-nozzle. The supply air pressure to the sub-nozzle was adjusted with a pressure regulator to a gauge pressure $294 \mathrm{kPa}$. The supply airflow rate $Q_{0}$ at this time was $0.98 \times 10^{-3} \mathrm{~m}^{3} / \mathrm{s}$ under standard conditions $(273.15 \mathrm{~K}$ and $101.3 \mathrm{kPa}$ ), and the upward injection angle $\theta_{z}$ of the sub-nozzle was about $8 \mathrm{deg}$.

In order to investigate the influence of the leakage to the profile reed's back or front on the airflow in the weft passage, the leakage was blocked with pasteboard (Cover). The conditions of the covering were (1) Non-Covered, (2) Back Cover Only (1) of Fig. 2), (3) Front Cover Only (2) of Fig. 2) and (4) Both Front and Back Covers (1) and (2) of Fig. 2). The measurement points of the air velocity distribution are shown in Fig. 2.

(1) The method of measuring velocity distribution and calculation of the flow rate

In order to measure the velocity distribution in the weft passage, a sub-nozzle was moved along the sley, and the position $X$, where the hot-wire probe was set, was established. The origin of measurement in the $Y Z$ plane was the position of $1 \mathrm{~mm}$ from the upper jaw of the profile reed, and $2 \mathrm{~mm}$ from the bottom part, as shown in Fig. 2. The measurement points were in a range from $0 \mathrm{~mm}$ to $-4 \mathrm{~mm}$ in $Y$-direction and from $0 \mathrm{~mm}$ to $4.5 \mathrm{~mm}$ in the $Z$-direction at an interval of $0.5 \mathrm{~mm}$, respectively, and the measurement points in the $Y Z$ plane numbered 90 in all. 29 points were measured in the $X$-direction at $5 \mathrm{~mm}$ interval from $10 \mathrm{~mm}$ to $150 \mathrm{~mm}$. The measurement points in the three-dimensional space totaled 2610 locations.

The velocity distribution behind the profile reed segment was measured in two dimensions on the $X Y$ plane, $0.5 \mathrm{~mm}$ away from the reed segment under the situation of the fixed sub-nozzle. In the $X Y$ plane, the 16 points at $1 \mathrm{~mm}$ interval from $-5 \mathrm{~mm}$ to $10 \mathrm{~mm}$ were chosen in the $Y$-direction, and 29 points at $5 \mathrm{~mm}$ interval from $10 \mathrm{~mm}$ to $150 \mathrm{~mm}$ were chosen in the $X$-direction. There were a total of 464 locations in the $X Y$ plane.

In the region of the weft passage, the hot-wire probe for velocity measurement was installed parallel with the $Z$-axis. Similarly, behind the profile reed segment, the hot-wire was set in parallel with the $Y$-axis. The position of the hot-wire was adjusted between reed dents at this time. The data processing in each measuring point used a sampling frequency of $2000 \mathrm{~Hz}$ and 1024 data.

Airflow rate $Q_{i}$ in the weft passage was calculated using the following formula from the time average air velocity $U_{i}$ measured at each point on the $Y Z$ plane at the distance $X$ from the sub-nozzle.

$$
Q_{i}=\iint U_{i} d Y d Z
$$

Similarly, leakage flow rate $Q_{b}$ behind the profile reed was calculated in consideration of the cavity ratio $s$ using the following formula.

$$
Q_{b}=\frac{s}{100} \iint U_{b} d X d Y
$$

\section{(2) Observation of the weft yarn tip position}

Compressed air was issued steadily from the sub-nozzle. A weft end was fixed on a line extended along the central axis of the weft passage (the fixed position was $X=-50 \mathrm{~mm}$, $Y=-1.25 \mathrm{~mm}$ and $Z=-2 \mathrm{~mm}$ ). When the yarn tips were at $X$ $=10 \mathrm{~mm}, 60 \mathrm{~mm}$ and near $100 \mathrm{~mm}$, their behavior was observed photographically (the shutter speed was $1 / 60 \mathrm{~s}$ and film sensitivity was ISO400). Cotton yarn of 220 tex was used for this test.

\section{Experimental Results and Consideration}

\subsection{The velocity and the flow rate in the weft passage}

\section{(1) Velocity distribution}

The maximum velocity $U_{m}$ in the $Y Z$ plane at each of the $X$ positions in the weft passage is shown in Fig. 3. The maximum velocity $U_{m}$ of the sub-nozzle jet in the weft passage increases rapidly at $X=30 \mathrm{~mm}$, and it achieves its highest value at $X=50 \mathrm{~mm}$, after which it decreases gradually in $X>50 \mathrm{~mm}$. In $X>70 \mathrm{~mm}$, the maximum velocities except in the case of the Both Covers are almost the same.

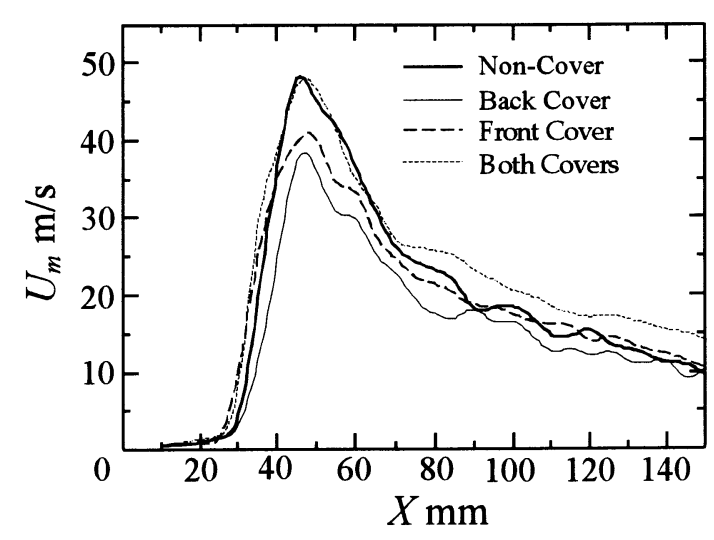

Fig.3 Maximum velocity distribution in the weft passage 


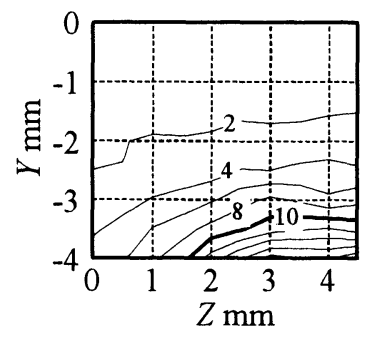

(a) $X=35 \mathrm{~mm}$

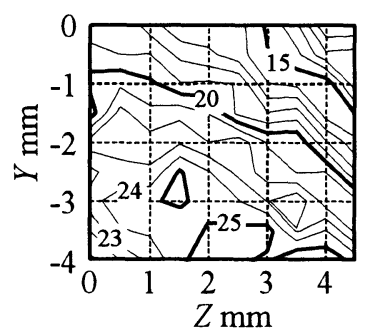

(e) $X=70 \mathrm{~mm}$

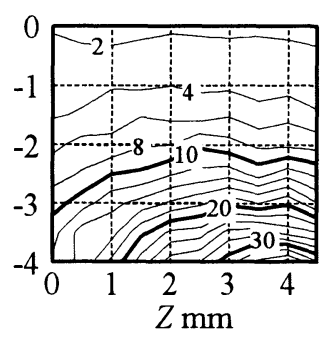

(b) $X=40 \mathrm{~mm}$

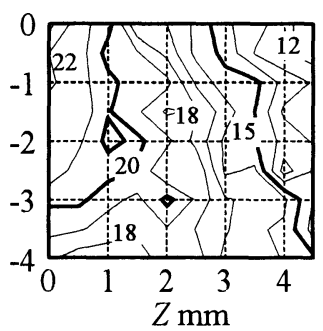

(f) $X=80 \mathrm{~mm}$

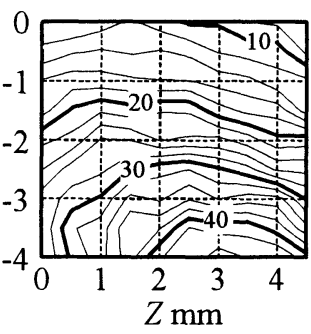

(c) $X=50 \mathrm{~mm}$

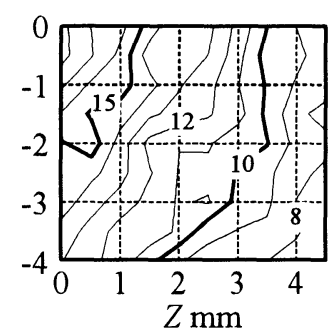

(g) $X=100 \mathrm{~mm}$

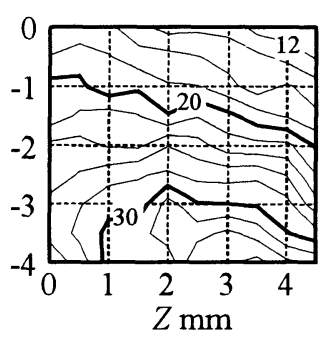

(d) $X=60 \mathrm{~mm}$

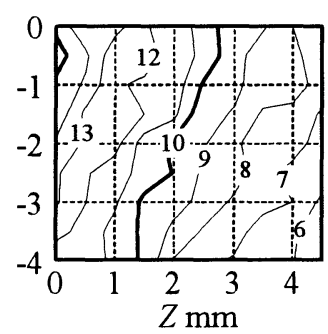

(h) $X=120 \mathrm{~mm}$

Fig. 4 Velocity contour lines in the weft passage without Cover

The highest value at $X=50 \mathrm{~mm}$ depends on the covering condition. In the cases of the Front Cover and the Back Cover, the highest value of $U_{m}$ is smaller than in the case of the Non-Cover. The highest value of $U_{m}$ in the case of the Both Covers is the same as that of the Non-Cover, and $U_{m}$ in $X>70 \mathrm{~mm}$ is larger than under other covering conditions. In the case of the Back Cover, the highest value of $U_{m}$ at $X=50$ $\mathrm{mm}$ is smaller than under other covering conditions, because the leakage to the front upper side of the profile reed segment increases when the leakage behind the profile reed segment is blocked. In the case of the Front Cover, increasing the leakage behind the profile reed reduces the air velocity in the direction of the weft insertion.

Figure 4 shows the contour lines diagram of the velocity $U_{i}$ in the weft passage in the $Y Z$ plane at $X$ positions that begin to exhibit increased maximum velocity $U_{m}$ in Fig. 3 in the case of the Non-Cover. The number in the figure is the velocity value $(\mathrm{m} / \mathrm{s})$. Although the center of the velocity contour lines in the weft passage is in the outside of the lower jaw $(Y=-4 \mathrm{~mm}$ and $Z=3.5 \mathrm{~mm}$ ) at $X=35 \mathrm{~mm}$, it begins to transfer gradually at $X=60 \mathrm{~mm}$, and it reaches inside the upper jaw $(Y=0 \mathrm{~mm}$ and $Z=0 \mathrm{~mm})$ at $X=80 \mathrm{~mm}$. This indicates that the position of the maximum velocity of the sub-nozzle jet moves in accordance with the form of the lower jaw part of the profile reed in $X<80 \mathrm{~mm}$ rather than linearly toward the bottom of the tunnel part (it is $Y=0 \mathrm{~mm}$ and $Z=0 \mathrm{~mm}$ in this experiment). And the maximum velocity position in $X>110 \mathrm{~mm}$ moves to the lower jaw side (the negative direction of $Y$ ) along the tunnel bottom side $(Z=0$ $\mathrm{mm}$ ) as shown in Fig. 5.

$Y$-coordinate value $y_{m}$ and $Z$-coordinate value $z_{m}$ of the maximum velocity point are shown in Fig. 5 . It is found that the coordinate values of the maximum velocity point are changed by covering conditions of the profile reed segment. The one point chain line in Fig. 5 shows the free jet axis of the sub-nozzle which is explained by the following formula derived from the upward injection angle $\theta_{z}$ of sub-nozzle, the

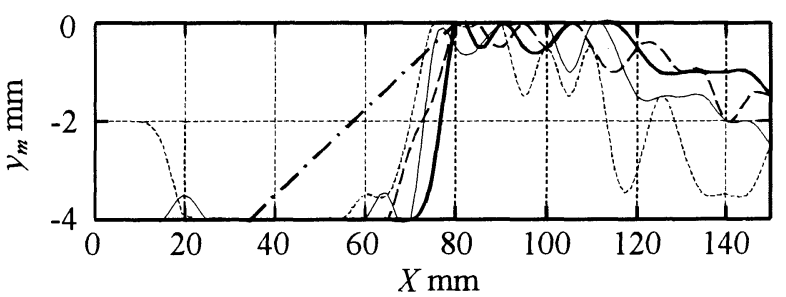

(a) $Y$ direction

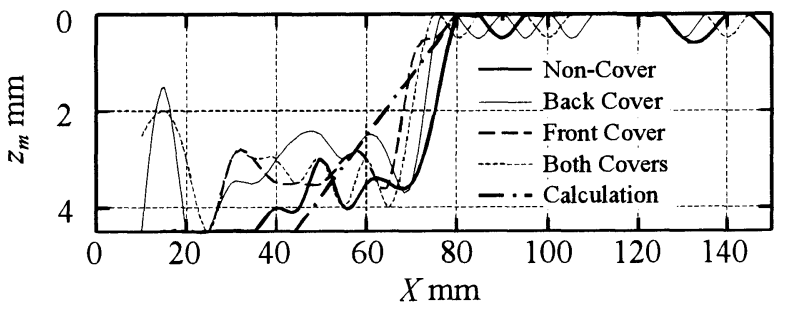

(b) $Z$ direction

Fig. 5 Position of maximum velocity along the weft passage

lateral injection angle $\theta_{y}$, the attachment angle $\theta_{a}$ and the coordinate value $\left(y_{0}, z_{0}\right)$ of the sub-nozzle's outlet.

$$
\begin{aligned}
& y_{m}=\left(\tan \theta_{y} \cos \theta_{a}+\tan \theta_{z} \sin \theta_{a}\right) X+y_{0} \\
& z_{m}=\left(\tan \theta_{y} \sin \theta_{a}-\tan \theta_{z} \cos \theta_{a}\right) X+z_{0}
\end{aligned}
$$

As shown in Fig. 5 (a), when $X<60 \mathrm{~mm}$, the maximum velocity position $y_{m}$ in the $Y$-direction of the profile reed segment is on the lower jaw side $(Y=-4 \mathrm{~mm})$ independent of the leakage state, and it is considerably different from the free jet axis. It moves to the upper jaw side $(Y=0 \mathrm{~mm})$ from the lower jaw side $(Y=-4 \mathrm{~mm})$ in $X=70$ to $80 \mathrm{~mm}$. It is considered that the reason for this is that the shape of the lower jaw part has influenced the jet from the sub-nozzle in $X<70 \mathrm{~mm}$. Furthermore, in $X>80 \mathrm{~mm}, y_{m}$ moves to the lower jaw side when the leakage to the back of the reed segment is cut off. Especially in the case of the Both Covers, $y_{m}$ greatly moves to the lower jaw side. 


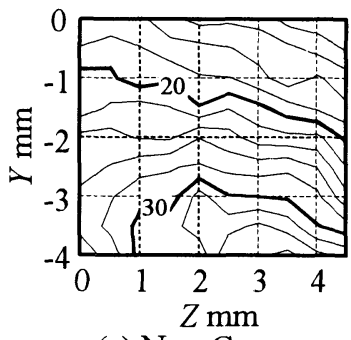

(a) Non-Cover

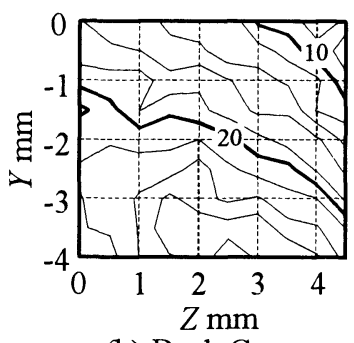

(b) Back Cover

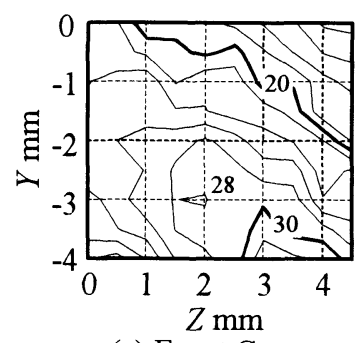

(c) Front Cover

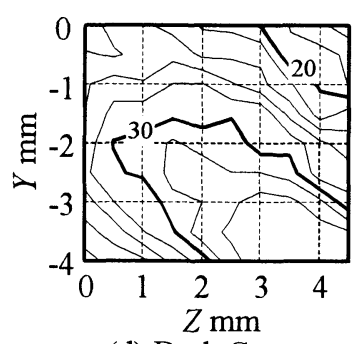

(d) Both Covers
Fig. 6 Velocity contour lines in weft passage at $X=60 \mathrm{~mm}$

In $X>80 \mathrm{~mm}$, the maximum velocity position $z_{m}$ in the $Z$-direction exhibits hardly any relationship to the leakage state from the tunnel part of the profile reed, as shown in Fig. 5 (b). When $X<80 \mathrm{~mm}$, the maximum velocity position $z_{m}$ is nearer to the free jet axis of the sub-nozzle compared with the $Y$-direction, and $z_{m}$ in the case of the Back Cover moves to the tunnel's bottom side of the profile reed segment $(Z=0$ $\mathrm{mm}$ ) from the vicinity of $X=30 \mathrm{~mm}$.

The contour lines diagram of the air velocity $U_{i}$ at $X=60$ $\mathrm{mm}$ shows that the maximum velocity position $y_{m}$ shown in Fig. 5 (a) begins to move from the lower jaw to the upper jaw as shown in Fig. 6. In this figure, (a) is for the Non-Cover, (b) for the Back Cover, (c) for the Front Cover and (d) for the Both Covers, and the numeric shows the velocity value $(\mathrm{m} / \mathrm{s})$. In the cases of the Non-Cover, the Back Cover and the Front Cover, the maximum velocity position $y_{m}$ is below $-4 \mathrm{~mm}$, and in the case of the Both Covers, it is $-3.5 \mathrm{~mm}$. And in the Z-direction, $z_{m}$ is $3.5 \mathrm{~mm}$ in the case of the Non-Cover, is $2.5 \mathrm{~mm}$ in the case of the Back Cover and is $3 \mathrm{~mm}$ in the cases of the Front Cover and the Both Covers. Therefore, the position of the maximum velocity in the direction of back and front ( $Z$ direction) moves to the inside of the tunnel part by cutting off the leakage from the profile reed.

Figure 7 shows the contour lines of velocity $U_{i}$ in the weft passage on the $X Y$ plane at $Z=0 \mathrm{~mm}$ under different covering conditions. The numeric in the figure shows the velocity value $(\mathrm{m} / \mathrm{s})$. In this figure, (a) is for the Non-Cover, (b) for the Back Cover, (c) for the Front Cover and (d) for the Both Covers. The center positions of velocity contour lines in the bottom of the profile reed segment are at about $X=50 \mathrm{~mm}$ under any leakage conditions as shown Fig. 7. Since the $Y$-coordinate value in this case is from $-2 \mathrm{~mm}$ to $-3 \mathrm{~mm}$, the sub-nozzle jet arrives at the bottom of the profile reed tunnel on the lower jaw side below the tunnel center. Except for Fig. 7 (d), the velocity on the upper jaw side $(Y=0 \mathrm{~mm})$ in $X>$

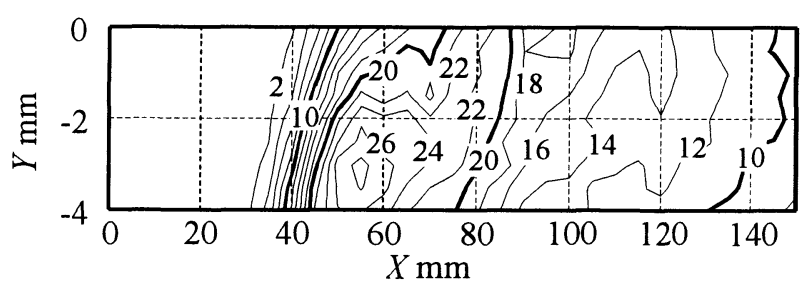

(a) Non-Cover

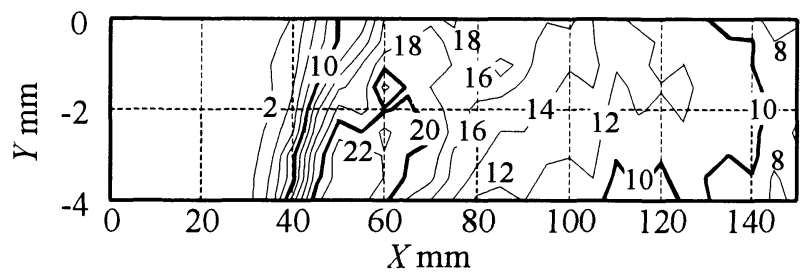

(b) Back Cover

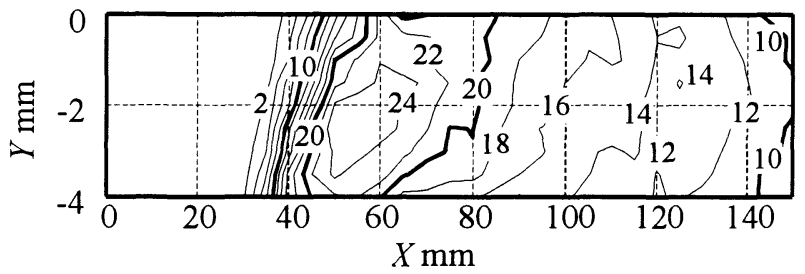

(c) Front Cover

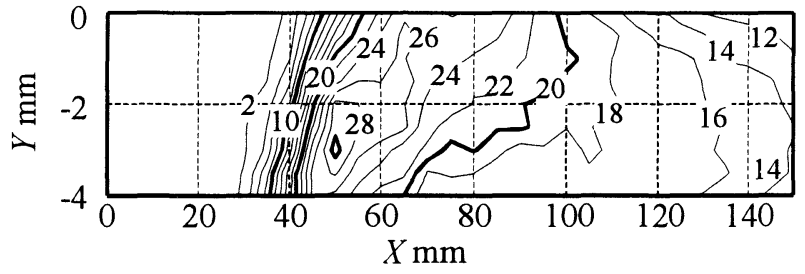

(d) Both Covers

Fig. 7 Velocity contour lines in the weft passage at $Y=0 \mathrm{~mm}$

$80 \mathrm{~mm}$ is higher than that on the lower jaw side $(Y=-4 \mathrm{~mm})$. In the case of the Both Covers in Fig. 7 (d), the velocity on the lower jaw side in $X>120 \mathrm{~mm}$ is higher than that on the upper jaw side.

Figure 8 shows the contour lines of velocity $U_{i}$ in the weft passage on the $X Z$ plane at $Y=0 \mathrm{~mm}$ under different leakage conditions similar to the data illustrated in Fig. 7, and the numeric in the figure shows the velocity value $(\mathrm{m} / \mathrm{s})$. The velocity contour lines on the $X Z$ plane at $Y=0 \mathrm{~mm}$ show that the velocity distribution in the weft passage differs according to the covering condition of the profile reed segment.

It is supposed that the maximum velocity position of the sub-nozzle jet exists on the free jet axis through the point of $X=80 \mathrm{~mm}, Y=0 \mathrm{~mm}$ and $Z=0 \mathrm{~mm}$, because the center position of velocity contour lines at $Y=0 \mathrm{~mm}$ are near $Z=0$ $\mathrm{mm}$ at about $X=80 \mathrm{~mm}$ under every covering condition. In the case of Both Covers in Fig. 8 (d), there is almost no leakage in the region of $X$ from 100 to $150 \mathrm{~mm}$. Therefore, the velocity in that region at $Y=0 \mathrm{~mm}$ seems to decrease gradually with no relation to $Z$, and the velocity on the front side $(Z=4.5 \mathrm{~mm})$ of the reed segment is higher than in the case of other leakage conditions.

From these results, it appears that the maximum velocity position of the sub-nozzle jet arrives at the tunnel bottom ( $Y$ 


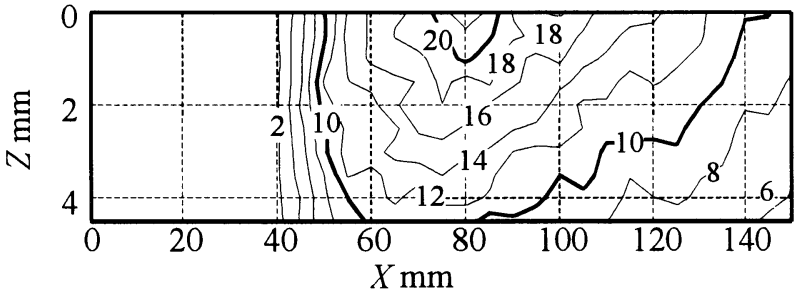

(a) Non-Cover

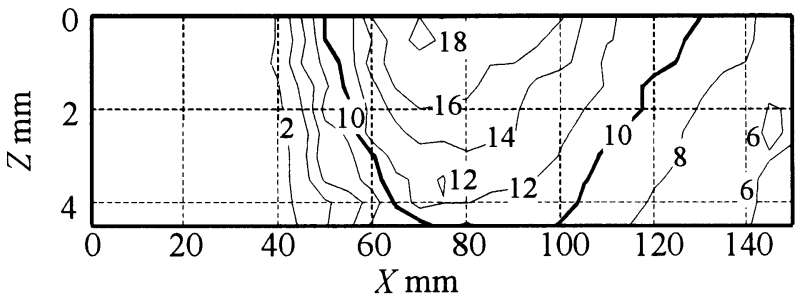

(b) Back Cover

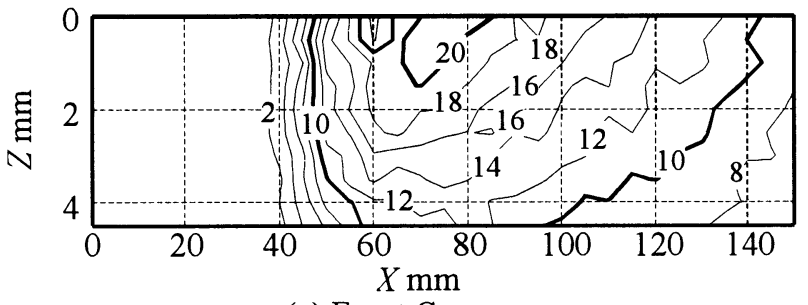

(c) Front Cover

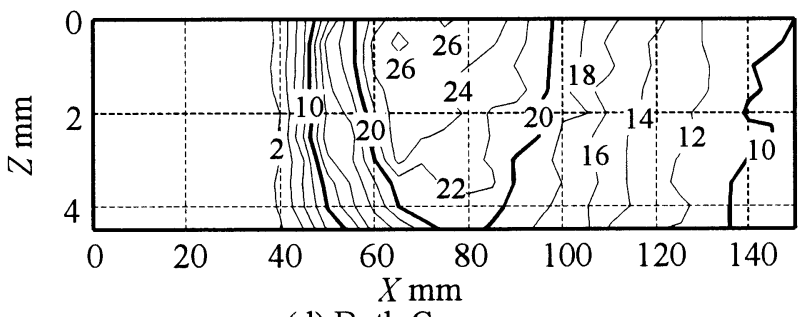

(d) Both Covers

Fig. 8 Velocity contour lines in the weft passage at $Z=0 \mathrm{~mm}$

$=0 \mathrm{~mm}$ and $Z=0 \mathrm{~mm}$ ) of the profile reed at about $X=80$ $\mathrm{mm}$ under every leakage condition. It is illustrated in Fig. 3 that the maximum velocity $U_{m}$ in the weft passage has highest value at $X=50 \mathrm{~mm}$ before the sub-nozzle jet arrives at the tunnel bottom of the profile reed segment.

\section{(2) Flow rate distribution}

The flow rate $Q_{i}$ in each section of $X$ was calculated by Eq. (1) from the measured velocity distribution on the $Y Z$ plane in the weft passage, and it is shown in Fig. 9 as a function of the distance $X$ from the sub-nozzle. The flow rate $Q_{i}$ decreases gradually, after reaching the highest value at $X=50$ $\mathrm{mm}$, as well as the maximum velocity distribution in Fig. 3 .

The flow rate $Q_{i}$ in the cases of the Non-Cover and the Front Cover is almost the same. The flow rate in the cases of the Non-Cover and the Back Cover in the same in $X>100$ $\mathrm{mm}$ also. In the case of the Both Covers, it is larger than in other cases.

\subsection{The velocity and the flow rate behind the profile reed segment}

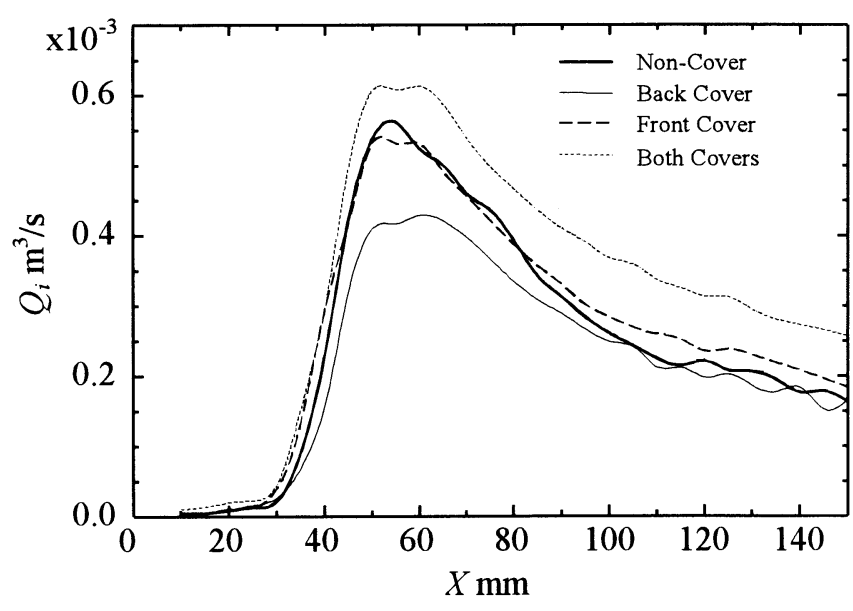

Fig. 9 Air flow rate in the weft passage

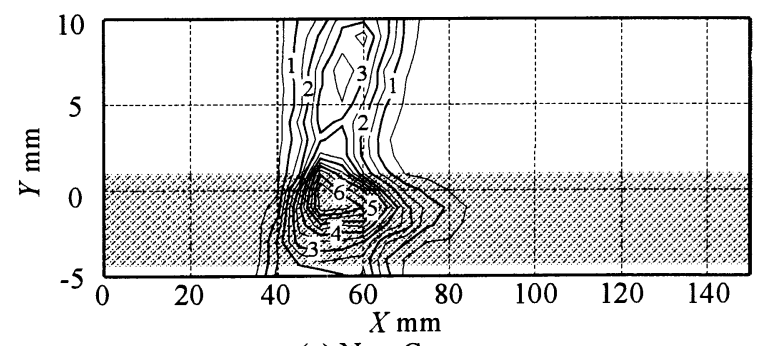

(a) Non-Cover

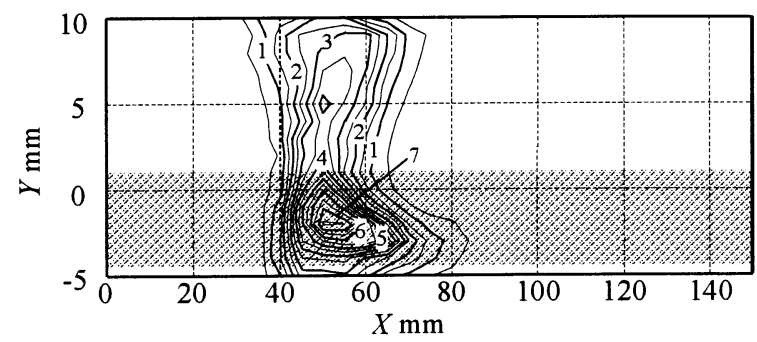

(b) Front Cover

Fig.10 Velocity contour lines behind the profile reed

\section{(1) Velocity distribution}

Figure 10 shows the contour lines of the velocity $U_{b}$ behind the profile reed segment in the cases of the Non-Cover and the Front Cover. In this figure, the gray part shows the bottom of the profile reed tunnel which forms the weft passage, and the numeric shows the velocity value $(\mathrm{m} / \mathrm{s})$. The center positions of the velocity contour lines in Figs. 10 (a) and (b) are near $X=50 \mathrm{~mm}$, and they correspond with the center position of the velocity contour lines at the bottom of the profile reed tunnel shown in Fig. 7. In the case of the Front Cover, the leakage behind the profile reed spreads in the region from $Y=0 \mathrm{~mm}$ to $Y=10 \mathrm{~mm}$ (upper part of the weft passage), and the center position of the velocity contour lines moves to the sub-nozzle side (negative direction in $X$ and $Y$ ). In the case of the Non-Cover, it is supposed that the leakage passes obliquely between profile reed dents because the $Y$-coordinate of the center of the velocity contour lines in the weft passage has a larger $Y$-value in comparison with Fig. 7. In the case of the Front Cover, it is thought that the leakage is parallel to the $Z$-axis between profile reed dents because the $Y$-coordinate of the velocity contour lines hardly 


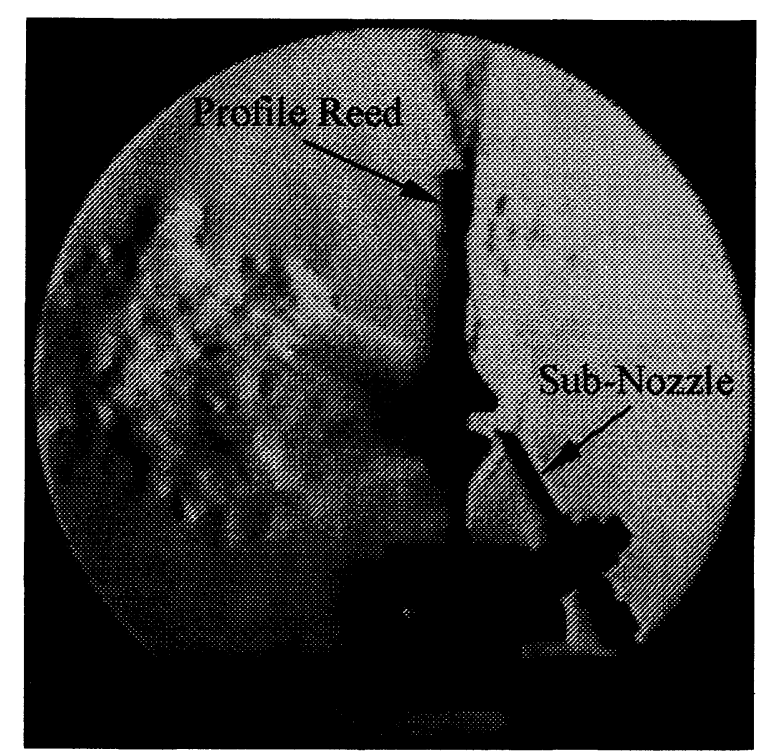

Fig.11 Schlieren photograph of leakage flow from the profile reed[6]

changed.

Figure 11 is a Schlieren photograph showing the leakage behind the profile reed reported in the previous paper [6]. Reed density was 13.5 dents/cm and dent thickness was 0.26 $\mathrm{mm}$. As reported in the previous paper, the leakage behind the profile reed goes in two directions (one is perpendicular to the reed, another is oblique). In this experiment, it is found that the maximum portions of the velocity contour lines behind the profile reed segment shown in Fig. 10 are at both the bottom part of the profile reed tunnel and its upper part near $X=50 \mathrm{~mm}$, and there are two leakage points at $X=$ $50 \mathrm{~mm}$

\section{(2) Flow rate distribution}

The leakage flow rate $Q_{b}$ behind the profile reed was calculated by Eq. (2) based on the velocity distribution behind the profile reed segment, and it is shown in Fig. 12 as a function of $X$-distance from the sub-nozzle. The leakage flow rate $Q_{b}$ increases rapidly at $X=40 \mathrm{~mm}$, and it decreases

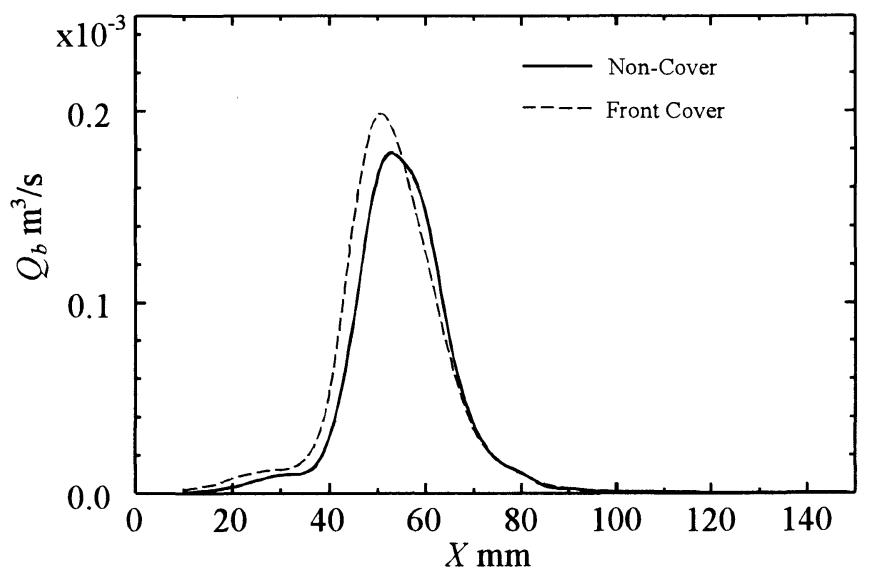

Fig.12 Leakage flow rate behind the profile reed rapidly after reaching its highest value at nearly $X=50 \mathrm{~mm}$, and it is zero in $X>90 \mathrm{~mm}$. It is found that $Q_{b}$ is increased by attaching the Front Cover, and in the case of the Front Cover it is larger than in the case of the Non-Cover in $X<60$ $\mathrm{mm}$. It is supposed that the highest value in the case of the Front Cover for the maximum velocity in the weft passage shown in Fig. 3 is smaller than in the Non-Cover because the leakage flow rate behind the profile reed is increased as shown in Fig. 12.

\subsection{Observation of the weft yarn position within the reed}

Figure 13 is the photographic observation of the behavior of the weft yarn tip in the profile reed in the case of the Non-Cover. The weft yarn tip is located at $X=10 \mathrm{~mm}, 60$ $\mathrm{mm}$, or $90 \mathrm{~mm}$. The position of the weft yarn tip in the profile reed is changed by the sub-nozzle jet. At $X=10 \mathrm{~mm}$, the weft yarn tip is pulled by the sub-nozzle jet, and located near the sub-nozzle on the lower jaw side of the profile reed segment. At $X=60 \mathrm{~mm}$, the weft yarn is bent by the sub-nozzle jet and the weft yarn tip is located on the upper jaw side. The bent position of the weft yarn is at about $X=35 \mathrm{~mm}$. And, in $X<15 \mathrm{~mm}$, the weft yarn is shaken violently by the sub-nozzle jet. Further, at $X=90 \mathrm{~mm}$, the weft yarn tip is located on the upper jaw side, and the whole weft yarn is also located on the upper jaw side of the reed tunnel bottom. Although the weft yarn tip is shaking only a little at this time, the whole weft yarn is pushed against the reed.

Figure 14 is the photographic observation of the behavior of the weft yarn tip in the profile reed in the case of the Front Cover. Similar to the observation in Fig. 13, the weft yarn tip

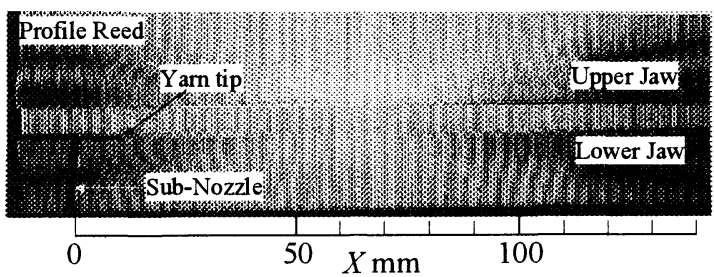

(a) Position of yarn tip of $10 \mathrm{~mm}$

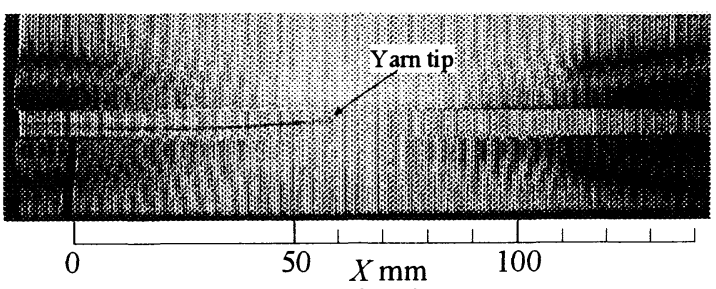

(b) Position of yarn tip of $60 \mathrm{~mm}$

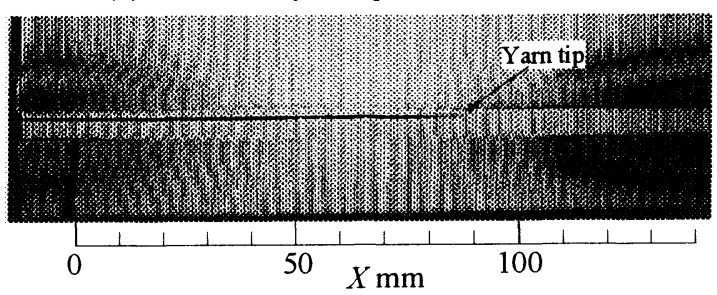

(c) Position of yarn tip of $90 \mathrm{~mm}$

Fig.13 Position of yarn tip in the weft passage without Cover 


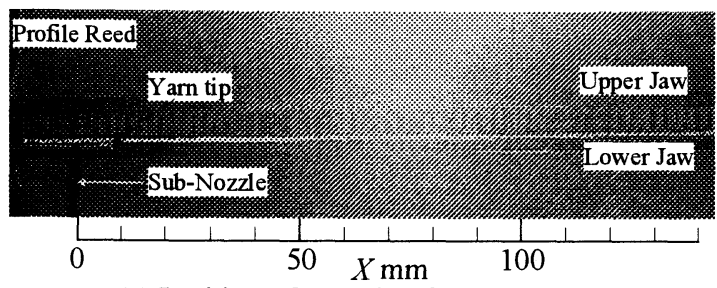

(a) Position of yarn tip of $10 \mathrm{~mm}$

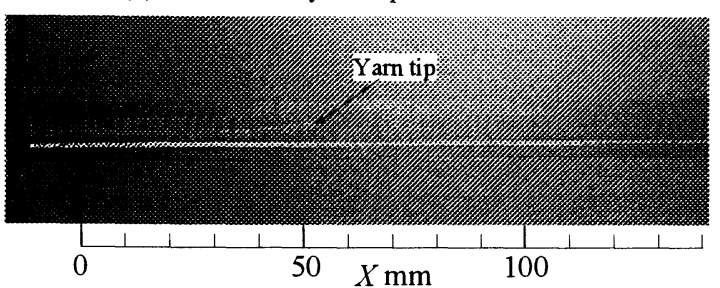

(b) Position of yarn tip of $50 \mathrm{~mm}$

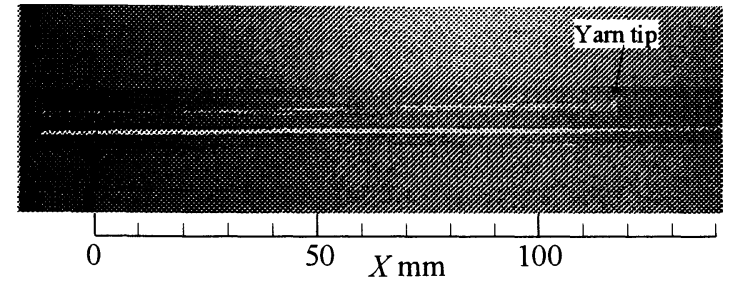

(c) Position of yarn tip of $110 \mathrm{~mm}$

Fig.14 Position of yarn tip in the weft passage with Front

Cover

is located on the sub-nozzle side of the lower jaw side at $X=$ $10 \mathrm{~mm}$, and located on the upper jaw side near $X=60 \mathrm{~mm}$, and is bent at about $X=35 \mathrm{~mm}$. At $X=110 \mathrm{~mm}$, the whole weft yarn is located on the upper jaw side. Although violent shaking of the weft yarn occurs in $X<15 \mathrm{~mm}$ as shown in Fig. 13, it is not observed in the case of the Front Cover, but shaking of the weft yarn tip is observed at $X=110 \mathrm{~mm}$.

It is supposed that the position of the weft yarn tip corresponds to the free jet axis as shown in Fig. 5, because its position in the weft passage changes near $X=35 \mathrm{~mm}$ as illustrated in both Figs. 13 and 14. In addition, in the case of the Both Covers, the airflow towards the outside of the profile reed tunnel became strong owing to a pressure rise in the weft passage, such that the weft yarn was blown out of the tunnel part, and it was impossible to observe a weft yarn tip position. It is hypothesized that the weft insertion is impossible in the case of the Both Covers when there is no leakage other than the open parts of the profile reed tunnel.

Under different leakage condition of the profile reed, although the flying position of the weft yarn doesn't change drastically, it is supposed that the shaking aspects of the weft as it flies are affected. It is further supposed that a weft yarn tip flying as observed in Figs. 13 and 14 can successfully travel the entire reed width as long as the attached pitch of the sub-nozzle is not less than $50 \mathrm{~mm}$. This last is supposed after taking velocity distribution measurement results into consideration, despite the fact that the experiment used only one sub-nozzle.

\section{Conclusion}

In order to realize an increase of flexibility and electric power reduction in AJL, the airflow in the profile reed tunnel that is the weft passage as well as the airflow behind the profile reed was measured. The influence of the air leakage to the front and back of the profile reed on the airflow in the weft passage was investigated. The relation between the velocity distribution in the weft passage and the weft yarn tip position was also investigated. Consequently, the following conclusions were obtained.

(1) The maximum velocity position in a section of the sub-nozzle jet measured until it arrives at the tunnel bottom of the profile reed $(X<80 \mathrm{~mm})$ moves not linearly but in accordance with the lower jaw form of the profile reed.

(2) In $X<60 \mathrm{~mm}$, the maximum velocity position $y_{m}$ is on the lower jaw side, but this is not affected by the air leakage, and is moved to the lower jaw side by closing the leakage behind the profile reed when $X>80 \mathrm{~mm}$. Furthermore, in $X$ $<80 \mathrm{~mm}$, the $z_{m}$ position changes closer to the free jet axis than $y_{m}$, and moves to the inside of the reed tunnel by blocking the leakage. In $X>80 \mathrm{~mm}$, it is not dependent on the leakage condition.

(3) Although the maximum velocity position of the sub-nozzle jet reaches the upper jaw side of the profile reed at $X=80 \mathrm{~mm}$, the position of maximum velocity and maximum flow rate in the weft passage are at $X=50 \mathrm{~mm}$, and the leakage flow rate behind the profile reed also has the maximum value at $X=50 \mathrm{~mm}$.

(4) If the front of a profile reed is covered, the leakage behind the profile reed is increased so that the maximum velocity in the weft passage will decrease in comparison to the Non-Cover condition.

(5) It is clear from the photographic observation that the flying positions of the yarn tip change corresponding to the free jet axis of the sub-nozzle jet in the profile reed tunnel.

(Acknowledgement) The authors gratefully acknowledge the support of Kiji Reed Co. Ltd. for this investigation.

\section{References}

[1] Ishida, M., Okajima, A.; Text. Res. J., 64, p. 10 (1994)

[2] Ishida, M., Okajima, A.; Text. Res. J., 64, p.88 (1994)

[3] Shintani, R., Donjou, I., Chikaoka, K., Okajima, A.; J. Text. Mach. Soc. Japan (Japanese Ed.), 47, T190 (1994)

[4] Shintani, R., Donjou, I., Chikaoka, K., Okajima, A.; J. Text. Mach. Soc. Japan (Japanese Ed.), 49, T57 (1996)

[5] Yoshida, K., Suzuki, F., Kawabata, S., Hasegawa, J.; J. Text. Mach. Soc. Japan (Japanese Ed.), 40, T125 (1987)

[6] Shintani, R., Okajima, A., Shintaku, S.; J. Text. Mach. Soc. Japan (Japanese Ed.), 53, T217 (2000) 